2012-12-14

\title{
Viewpoints: Liberatory Ensemble and Character
}

Christopher Layton Clark

Brigham Young University - Provo

Follow this and additional works at: https://scholarsarchive.byu.edu/etd

Part of the Educational Leadership Commons

\section{BYU ScholarsArchive Citation}

Clark, Christopher Layton, "Viewpoints: Liberatory Ensemble and Character" (2012). Theses and Dissertations. 3858.

https://scholarsarchive.byu.edu/etd/3858

This Dissertation is brought to you for free and open access by BYU ScholarsArchive. It has been accepted for inclusion in Theses and Dissertations by an authorized administrator of BYU ScholarsArchive. For more information, please contact scholarsarchive@byu.edu, ellen_amatangelo@byu.edu. 
Viewpoints: Liberatory Ensemble and Character

Christopher L. Clark

\begin{abstract}
A dissertation submitted to the faculty of
Brigham Young University

Doctor of Philosophy

Clifford Mayes, Chair

Rodger Sorensen

LeGrand (Buddy) Richards

Amy Peterson Jensen

Ellen Williams
\end{abstract} in partial fulfillment of the requirements for the degree of

Department of Educational Leadership and Foundations

Brigham Young University

December 2012

Copyright $@ 2012$ Christopher L. Clark

All Rights Reserved 


\author{
ABSTRACT \\ Viewpoints: Liberatory Ensemble and Character \\ Christopher L. Clark \\ Department of Educational Leadership and Foundations, BYU \\ Doctor of Philosophy
}

This dissertation, submitted in article format, explores how the physical movement theories of Anne Bogart's Viewpoints may lead to a liberatory setting, one which echoes the theories of Paolo Freire, for college theatre students. It examines whether Viewpoints is effective in creating a studio classroom culture and whether the Viewpoints exercises can lead to a heightened clarity in individual performance, with a much more satisfying and involved learning experience for students of the theatrical arts. In addition, this dissertation applies the theory of Mead's symbolic interactionism to the discoveries that students make while using Viewpoints exercises. Research methods include autoethnography, analysis of case studies, and examination of interview data from three college directors and thirteen student actors who have trained and used Viewpoints in rehearsal.

Keywords: Anne Bogart, Viewpoints, liberatory pedagogy, Paolo Freire, George Herbert Mead, symbolic interactionism, autoethnography, college theatre, student actors 


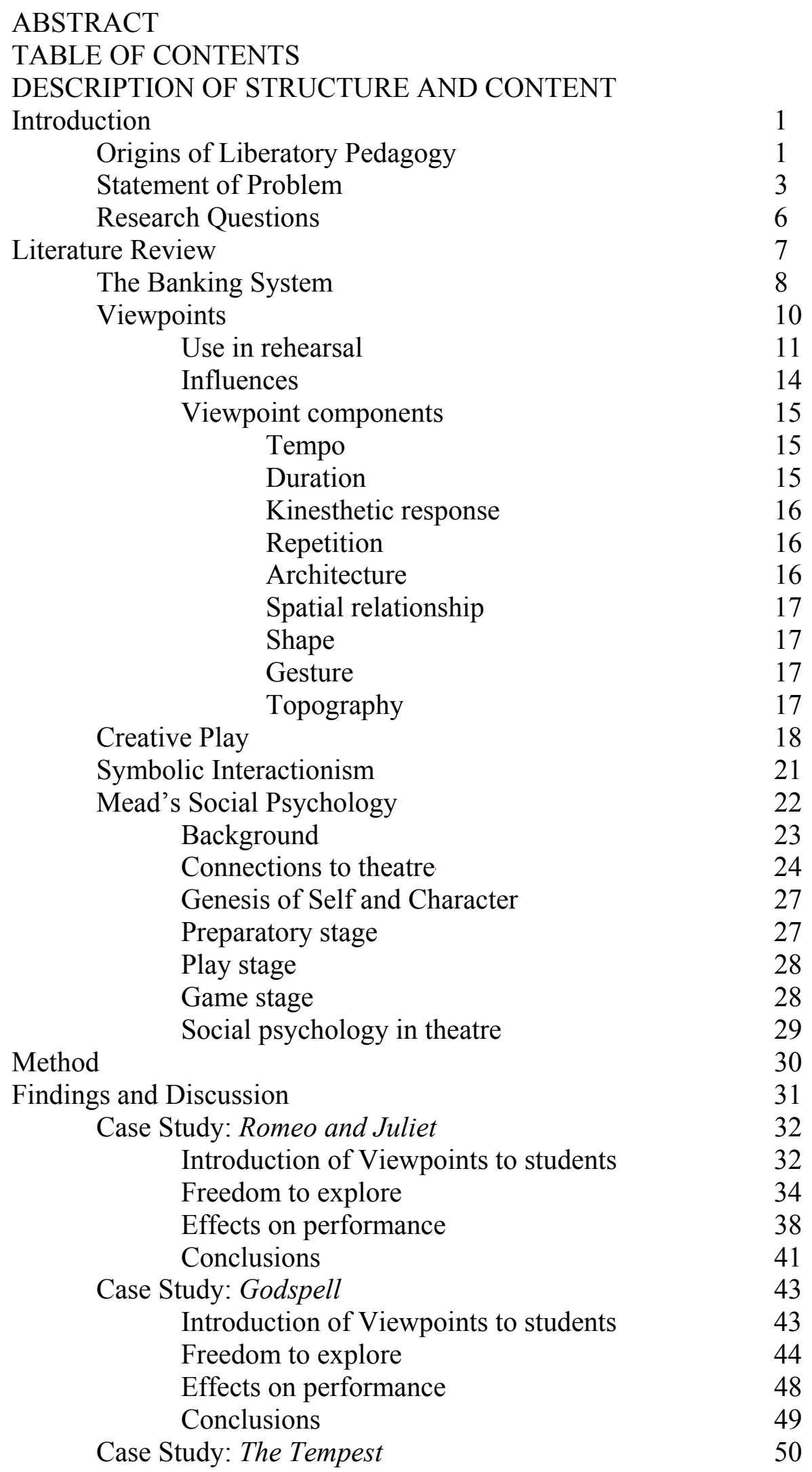


Conclusion

References 


\section{Introduction}

This dissertation addresses the merging of art, character, and self in the college theatrical rehearsal. The physical movement theories of Anne Bogart's Viewpoints have shown that improvisation, movement study, and ensemble exercises can play a vital role in creating a liberatory studio rehearsal environment, in which professional actors collaborate, create, and express ideas, and where they come to understand who they are as individuals, what they can become as characters, and what they can do as a team.

Theatre, if it is to achieve full appreciation, has to be dealt with beyond the boundaries of plot. While audiences need plot to understand storytelling and narrative, plot does not always ensure actor fulfillment; actors need to have an emotional connection to their work. Rehearsals that utilize theatrical physicalization ensure that the emotional constituents and thematic elements of a performance are given as much emphasis as plot structure and character are. The Viewpoints theory breaks physical action into nine components: tempo, duration, kinesthetic response, repetition, shape, gesture, architecture, topography, and spatial relationship. The Viewpoints exercises, which are used directly in rehearsal, ask actors to physically interact with each other and respond spontaneously and impulsively. The purpose of Viewpoints is to train performers, build ensemble, and create movement for the stage.

\section{Origins of Liberatory Pedagogy}

The Brazilian educator Paulo Freire struck a strong chord with educators in the second half of the twentieth century with his Pedagogy of the Oppressed (2000), which examined the role of educational authority and its relationship with the student subject. Freire looked at various types of oppressed groups and cited students of the "banking system" as one of them. In the "banking system," students are required to learn via rote memorization and then store 
information until it is demanded of them. Liberatory pedagogy, in which students are encouraged to speak freely, devise, and bring their autobiographical narratives to their education, grew from Pedagogy of the Oppressed. This pedagogy aims to make the classroom a place where students are "learning to perceive social, political, and economic contradictions, and to take action against the oppressive elements of reality" (p. 34). The rehearsal hall, as a means of education, needs the same focus and "liberation" as the classroom does, as theatre students explore social relationships, make political discoveries, and improvise within the realms of reality and illusion. They need to be inspired and "illuminated" in the same way Freire (1986) proposes:

In liberating education, we do not propose mere techniques for gaining literacy or expertise or professional skills or even critical thought. The methods of dialogical education draw us into the intimacy of the society, the raison d'etre of every object of study. Through critical dialogue about a text or a moment of society, we try to reveal it, unveil it, see its reasons for being like it is, the political and historical context of the material. This for me is an act of knowing, not a mere transfer of knowledge or a mere technique for learning the alphabet. The liberating course 'illuminates' reality in the context of developing serious intellectual work. (p. 13)

This "illumination of reality" is often the aim of most theatre practitioners. In order to avoid what theatre innovator Peter Brook (1996) called "deadly theatre" (the staid, unoriginal, top-down theatrical pieces that represent much of contemporary practice), directors are continually looking for ways to innovate and create. College theatre professors, in particular, have the challenging expectation to produce commercially viable products while educating and training students through the process. Many struggle with the lack of time, lack of money, and 
lack of skill to give these students the opportunity to learn how to work together to create something vital and educative.

Liberatory pedagogy endeavors to make "the classroom a democratic setting where everyone feels a responsibility to contribute" (hooks, 1994, p. 39) and, in the theatre, opens the rehearsal process to the possibility of student voice and idea. In a liberatory setting, student/actors are encouraged to contribute, and director/teachers must relinquish some element of control. There must be willingness on both sides to be vulnerable, to ask questions, and to understand that there will be problems and questions for which there may not always be solutions. Directors must create an atmosphere that empowers students to interact vocally, physically, and emotionally. Viewpoints, a very physical technique, may do just that: encourage students to process their creative choices instinctively and to physicalize their ideas while interacting kinesthetically with others.

\section{Statement of Problem}

In the fall of 2006, I was assigned to direct William Shakespeare's The Tempest in my new position as a tenure-track faculty at Utah Valley University. Because I have training and interest in original Elizabethan (or, in this case, Jacobean) practice, I determined that I would cast the show entirely with male student actors. My concept was that the production would give our audience an experience fairly similar to the one they would have had if they had attended The Tempest when it premiered in 1611.

Once the show was cast, however, I found some difficulty in getting a group of young student actors to work together as a team, or what in theatre is called an "ensemble." This was partially due, I felt, to the fact that they seemed intimidated to work with all men; there was a sense of machismo that prevented them from opening up or being vulnerable in their 
performance. While they were willing to try to build a cohesive ensemble, I sensed a real reluctance to commit to creating a brotherhood of performers. This problem was compounded by the fact that I, as a director, had little time to spend in rehearsal developing their competence as a group.

As a college theatre director I spend much of my time working with student designers, stage managers, and producers; my time with student actors never seems to be enough. As a result I often cast productions with actors that can perform on autopilot. This solves the problem much of the time but does little to help develop novice actors or students who have great capability but need more encouragement and attention. As both a director and an educator, I find this frustrating.

My initial problem with The Tempest is not uncommon. Most college and university theatre professors are hired not only to teach, but also to produce theatre for the school. Our production, and the quality thereof, is often factored into our reappointment, tenure, and promotion. College directors are expected to produce theatre pieces that are commercially viable and of strong artistic merit and that can also teach and train student actors to become professionals. Our job as teachers includes teaching through performance; our students' education occurs both in the classroom and on the stage. Unfortunately, many college directors find themselves sacrificing the educational elements of theatre in order to create productions that will be financially profitable for their department or artistically innovative for their peer reviews. The student experience often gets lost in the mix.

This problem is not a concern in the professional world, where theatre is expressly a business. Professional directors may hope that their actors have a fulfilling experience, but the bottom line is mercenary. Without funding, ticket sales, and promotion, there is little chance that 
the theatre piece will survive. In academia, however, the goal can and should be geared toward the student experience. Students enroll in theatre programs in order to eventually work professionally. Without meaningful encouragement and experience, however, many talented students switch majors or leave school altogether. An opportunity to teach has been missed when directors focus all their time and energy on budgets and funding.

This loss of student actors would not be a concern for most people—what's one less potential starving actor? - unless they consider that many theatre undergraduates go on to graduate programs in teaching, medicine, social work, and law. Opportunities to learn teamwork, collaboration, compassion, and creativity have been replaced by lessons of profit and loss, and this can impact teachers, doctors, social workers, and lawyers, all of whom work in fields in which communication, collaboration, and insight are necessary, even compulsory, to success. These students will have missed the opportunity to learn about themselves, learn about others, build a team of creative partners, and produce something of artistic merit with personal satisfaction and ownership. Theatre has been called a pulpit for the modern man; it is also a classroom, both onstage and off.

In order to solve my problem and create a collaborative environment for the ensemble, I turned to Anne Bogart's Viewpoints. I was first introduced to Viewpoints at the Steppenwolf Summer Academy at Fresno State University in the summer of 2005. My instructor, Kim Rubenstein, taught an intensive class where we as students came to understand each of the nine Viewpoints intricately and then found ways to incorporate them into performance. While this was happening, we were also creating an incredible emotional bond that was tangible onstage in our performances. I knew that the quality of our final performance was directly related to the comfortable atmosphere of our rehearsal hall, where we were encouraged to listen, respond, 
create, explore, and receive feedback in a positive and productive way. Because Viewpoints provided such positive results for me, I decided to explore whether it would be an effective solution for my students' experience in The Tempest.

This dissertation begins with a look at collaborative environments in the arts, with special emphasis on Studio Thinking: The Real Benefits of Visual Arts Education by Hetland, Winner, Veenema, and Sheridan (2007) and its relationship to Freire's liberatory pedagogy. The problems of the banking system (Friere, 2000) are then laid out. Following this, the types of physical methods, movement, and improvisational activities in Viewpoints are explained, with a detailed look at each of the nine elements. There is then a discussion of the relationship Viewpoints has to creative play. Viewpoints is examined in the context of the social psychology of George Herbert Mead's (1967) studies of group life. It also considers, through Herbert Blumer's (1986) and J. P. Hewitt's (2000) symbolic interactionism, the relationship of Viewpoints to natural human behavior. After the methods of this study are explained, three case studies are presented wherein college directors used Viewpoints in rehearsals, including feedback given from two live, qualitative interviews with college directors and eleven asynchronous interviews via email with former students. The study concludes with my own observations in using Viewpoints to create a liberatory rehearsal, with some recommendations for directors who are keen to try it.

\section{Research Questions}

This work explores the following research questions:

1. Is Viewpoints effective for college students?

2. To what extent are the rehearsal processes liberatory? 
Viewpoints: Liberatory Ensemble and Character

3. Can Viewpoints offer these students a stronger sense of group, as well as a heightened clarity in individual performance, with a much more satisfying and involved learning experience in the theatrical arts?

4. Does the use of Viewpoints increase comprehension of the work and selfactualization of the actors?

\section{Literature Review}

This dissertation is rooted in four major sources of literature: Paulo Freire's Pedagogy of the Oppressed (2000), Anne Bogart's The Viewpoints Book (2005), Herbert Blumer's Symbolic Interactionism: Perspective and Method (1986) and G.H. Mead's Mind, Self, and Society: From the Standpoint of a Social Behaviorist. Each of these works will be explored in more depth in the following sections, with an additional section exploring "creative play," which refers to Peter Brook's The Empty Space: A Book About the Theatre: Deadly, Holy, Rough, Immediate (1986), J. Campbell's The Hero with a Thousand Faces (2008), E. Goffman's Behavior in Public Places: Notes on the Social Organization of Gatherings (1966), and Millman's Body Mind Mastery: Creating Success in Sport and Life (1999), among others.

Freire (2000) focuses on the idea that students in the current educational system are the victims of an oppressing arrangement. The oppressors are represented by teachers, administration, and an overall system that forces them to learn in one particular learning style, with little or no collaboration or constructive interaction between teacher and student. Freire also rejects the "banking approach" to education, where students simply show up for class and sit passively while they are instructed. According to Freire, this kind of top down, oppressive educational methodology will never lead to "praxis," or informed action. 
Viewpoints: Liberatory Ensemble and Character

It is obviously very important to refer frequently and substantially to Bogart (2005) to understand what Viewpoints is and how it works. Bogart writes briefly about the history and development of Viewpoints, and then continues to dissect each component of her method. When the nine Viewpoints components are understood individually they are more easily understood as a group as well; each Viewpoint component combines with the other eight to create interesting stage movement, collaborative exercises, and aesthetically pleasing stage picturization.

Blumer (1986) introduces the idea of social interaction. Humans constantly create social meanings and relationships from the encounters they have on a daily basis. These encounters are codified and interpreted, but these codes and interpretations are unique to each individual. There are essentially three main points, however: Humans interact with other individuals. These interactions lead to meaning. These meanings are handled and modified by each individual. This is essentially the basis of all human interaction; humans are making connections with other humans, and then creating meaning from that. Mead (1967) also explores these avenues of human connection; with special emphasis on both the verbal and non-verbal clues individuals send and receive through interaction. Mead's notion of "social psychology" is also rooted in the idea that humans create and cooperate when they interact, and that they then share in the meanings created once the interaction is complete.

\section{The Banking System and the Studio Classroom}

The current climate of director/student interaction in rehearsal mirrors Freire's (2000) "banking system” almost exactly:

1. The director directs, and the students are directed;

2. The director knows everything, and the students know nothing; 
Viewpoints: Liberatory Ensemble and Character

3. The director thinks, and the students are thought about;

4. The director talks, and the students listen-meekly;

5. The director disciplines, and the students are disciplined;

6. The director chooses and enforces his choice, and the students comply;

7. The director acts, and the students have the illusion of acting through the action of the director;

8. The director chooses the program content, and the students (who were not consulted) adapt to it;

9. The director confuses the authority of knowledge with his or her own professional authority, which she and he sets in opposition to the freedom of the students;

10. The director is the subject of the learning process, while the pupils are mere objects.

This climate of a "banking rehearsal" has the potential of robbing students of valuable learning experiences, and it sends them the message that they are unnecessary in the process of creating theatre. Actors become puppets in a banking system of directorial authority. The use of Viewpoints disrupts this banking system and may lead to a more liberatory rehearsal.

This liberatory rehearsal, created through Viewpoints in an academic setting, can also be regarded as the creation of a "studio" classroom. As theatre educators and directors are responsible for creating teaching and training opportunities in a safe and productive environment; this is a natural fit for the Studio Classroom as outlined by Hetland et al. (2007). By creating this environment, the Studio Classroom can give theatre students the opportunity to engage in physical and verbal exercises and activities as they learn to use their voices, their bodies, and their imagination. The Studio Classroom engages them in storytelling and improvisation that connects to who they are as individuals. They create art that has meaning and 
import to them. The Studio Classroom gives students the opportunity to see potential—-both in themselves and in their craft-so that they can create. These students can also learn the necessity of observation, creating a visual context for what they see and experience and assigning what Blumer (1986) calls “meaning." They learn to observe and comment on others' work, and are given the chance to judge their own efforts. Students' work in the theatre should push them, encourage them, and challenge them. Through this entire process are they learning more about not only the validity of their own talent but also of the art form itself.

\section{Viewpoints}

Viewpoints, a system devised to train actors and facilitate movement, also proves to be effective at fostering an ensemble that can create and collaborate effectively in a studio rehearsal. "Viewpoints" is a series of improvisational activities and techniques that focus on human movement and physical expression. Based on the work of choreographer Mary Overlie in the 1970s, Viewpoints was created by directors Anne Bogart and Tina Landau in the late 1980s with three goals: to train performers, to build ensemble, and to create movement for the stage. Rather than jumping into traditional blocking (the precise movement and positioning of actors on a stage), Viewpoints opens up these physical choices to the actors themselves. They stand when they like, sit where they like, and move how they like. These choices are introduced in a series of physical exercises which can last anywhere from a thirty-minute session to several hours, depending on what the director hopes to accomplish. Viewpoints was born from a series of questions or "problems" that the two directors had encountered in the state of current theatre practice:

1. The Americanization of the Stanislavski system.

2. Lack of ongoing actor training. 
Viewpoints: Liberatory Ensemble and Character

3. The word "want" and its effect upon rehearsal atmosphere and production. (Bogart \& Landau, 2005, p. 15)

The Russian theatre director Constantin Stanislavski had developed an acting style in the early twentieth century that focused on realism and naturalism; his exercises demanded that actors relinquish control, connect to their scene partners, and find an inner truth. American practitioners, however, took this style and made it into something that Bogart and Landau found selfish: the "Method," in which actors focused less on their fellow actors and more on their own choices, their own objectives, and their own "wants." This, Landau and Bogart felt, rendered the art of acting selfish and disconnected again.

Through composition, which is a method for creating new work involving selecting and arranging the separate components of theatrical language into a cohesive work of art for the stage, Bogart and Landau identified nine physical "Viewpoints." These Viewpoints represent certain principles of movement through time and space. They were then assigned names, which constituted a language for talking about what happens onstage (Bogart \& Landau, 2005). The Viewpoints were intended to help the actors create a physical awareness, to give them the ability to identify physical choices, and to determine what these choices represent to an audience.

Use in rehearsal. Viewpoints was created for the use of the New York City-based SITI (Saratoga International Theater Institute) Company and has since been embraced by many major theatre organizations, including the American Repertory Theatre, New York University, and, most specifically, the Steppenwolf Theatre Company of Chicago. Viewpoints is also being taught as movement practice in several University BFA and MFA programs and is currently being used for professional, semi-professional, and community staging and practice as well. 
Viewpoints: Liberatory Ensemble and Character

Bogart has written several articles and books dealing with her work with Viewpoints. In A Director Prepares (2001), she writes about the process of Viewpoints in a rehearsal setting:

I am interested in the artistic process. In order to approach the theatre as artists, we should have a good look at our tools and how we make decisions. How do we approach one another in the arena of a rehearsal or on a stage? How do we begin, how do we proceed, and "what are our allies?” (Bogart, 2001, p. i)

These questions are inherently important for any director as he or she approaches a rehearsal process. It's very difficult for many directors to simply begin; there may be awkwardness with a new cast, questions about how to approach the material, and a lack of concrete ideas for the look and feel of the show. Having tools to get started is incredibly valuable for a director. Theatre, when it is given correct preparation and the right approach to rehearsals, can be transformative. Bogart (2001) continues:

I regard the theatre as an art form because I believe in its transformative power. I work in the theatre because I want the challenge of decisiveness and articulation in my daily life. Directing chose me as much as I chose it. We found one another. I like to watch. I like to study. I like to meet people in the charged atmosphere of a rehearsal room or in a theatre. (p. 1)

She makes the point that theatre raises questions but, if done correctly, can also answer them:

I wanted to approach the theatre as an artist does, so I began to study the tools we have inherited and the procedures we use to make work in the theatre. I also studied how artists in other fields do what they do - how they think and how they create. I looked for helpful allies in the artistic process. How do we approach one 
another in the arena of a rehearsal or on a stage? How do we begin and then how do we go on?

As a director in the theatre I have encountered certain consistent problems that just do not go away. I have found myself repeatedly face to face with issues about violence, memory, terror, eroticism, stereotype, embarrassment and resistance. Rather than avoiding these problems I have found it fruitful to study them, and this study has changed the way I approach all my work in the theatre. The problems became allies. (p. 2)

These "allies" Bogart discusses can come in many forms. For many theatre practitioners, they are found in the local theatre community. Other actors, directors, and designers can often help directors solve problems as they prepare for a rehearsal process. But practitioners outside of theatre (musicians, painters, dancers, filmmakers, among many others) can have a resounding effect on their work as well. These "allies" can help ask and answer questions, or give the directors new ways to approach their work.

Finally, Bogart (2001) examines the arts in the face of the current state of modern media: I want an artistic explosion. Our high technology lifestyle demands a theatre experience that cannot be satisfied by video and movie screens. I want acting that is poetic and personal, intimate and colossal. I want to encourage the kind of humanity on the stage that demands attention and that expresses who we are and suggests that life is bigger....I want to find resonant shapes for our present ambiguities. (p. 39)

Most directors would agree with Bogart. We want our work to be resonant and innovative. We want to plumb the depths of our students' abilities and talents. Obviously we 
want to touch an audience and leave an impact, but in an academic setting it's vital that we also touch the lives of our students through the performance. We want them to find their own humanity onstage and create the resonant shapes that Bogart is talking about. The directorial process becomes, essentially, about finding the right tools to do so.

Influences. There has also been much written that inspired Viewpoints, as well as much written that has been inspired by it. Krasner (2006) looked at the way Viewpoints unites a cast and a director and made a connection from the parts to the whole. Dealing with ensemble, Krasner focused on how individual work can enrich group work in a rehearsal setting. Krasner also accepted the need for work like Viewpoints, but was cautious to let modern methods of actor training supersede older established forms:

Teachers and actors nurtured and raised on action-based pedagogy such as the Method more often than not prove highly effective when encountering the range of theatre forms. While we must continually adapt and transform the way we create and the way we teach, actors have always learned to play actions. (Krasner, 2006, p. 227)

Arnheim's (1997) work focused on visual thinking, which relates to Viewpoints almost entirely. More than just "looking" or "seeing" an object, Arnheim explored the shape and order of visual exploration. He also wrote about how this is perceived by both actor and audience. Kingdon (2004) spoke of Viewpoints as a problem solver, claiming that "Directors should have no hesitation admitting they are wrong - actors and crew will support people whose critical eye extends to themselves" (p. 161). Social constructionist Herbert Blumer (1986) looked at theatre practitioners, including Bogart, and their usage of improvisation and game-playing exercises. He considered how these practitioners create dramatic scenarios that "possess a surrealistic logic as 
Viewpoints: Liberatory Ensemble and Character

a means of creating non-naturalistic languages of physical theatre" (Gordon, 2006, p. 213). All of these observations of the nature and purpose of theatre give us a sense that theatre is more than just entertainment; it's a social contract. Actors explore, create, and tell stories, and audiences interpret and define what they see. But both groups have to do their part for it to work at all. And it often comes down to teachers and directors to make sure that this contract is happening in the first place.

Viewpoint components. In an effort to understand each compositional element of Viewpoints, it may be helpful to introduce them individually. Each Viewpoint falls into one of three categories: time, space, and shape (see table 1).

Tempo. Bogart (2005) defined tempo as "the rate of speed at which a movement occurs; how fast or slow something happens onstage" (p. 17). How quickly will the action take place, and how will this tempo affect the audience's understanding of the character?

Table 1

Categories of Viewpoints

\begin{tabular}{|c|c|}
\hline Categories & Viewpoint components \\
\hline$\vec{\Xi}$ & $\begin{array}{l}\text { Tempo } \\
\text { Duration } \\
\text { Kinesthetic response } \\
\text { Repetition }\end{array}$ \\
\hline Space & $\begin{array}{l}\text { Architecture } \\
\text { Spatial relationship } \\
\text { Topography }\end{array}$ \\
\hline Shape & $\begin{array}{l}\text { Shape } \\
\text { Gesture }\end{array}$ \\
\hline
\end{tabular}


Viewpoints: Liberatory Ensemble and Character

Duration. Duration involves the element of time, but adds an element of length. Bogart defined duration as how long a movement or sequence of movements continues. If a group is working as an ensemble and is together in tempo, duration asks how long the group will stay in that tempo before shifting to another one.

Kinesthetic response. Kinesthetic response, which Bogart defined as a spontaneous reaction to external motion, is at the heart of Viewpoints. While tempo deals with how fast, and duration deals with how long, kinesthetic response deals with when. The introduction of kinesthetic response is crucial, as it requires that actors shift their focus entirely away from their own choices and movement to that of their fellow actors. The purpose of kinesthetic response is to help actors look beyond themselves. It demands that actors work as a team and be open to external stimuli.

Repetition. Repetition, in Viewpoints, is the repeating of something onstage. Repetition, as Bogart defined it, can be interpreted in two ways:

a. Internal repetition: repeating a movement within your own body.

b. External repetition: repeating the shape, tempo, gesture, etc., of something outside your body.

Architecture. Architecture, in Viewpoints, is the physical environment in which an actor works and how awareness of this environment affects movement (Bogart, 2005). Bogart defined architecture in five ways:

a. Solid mass: Walls, floors, ceilings, furniture, windows, doors.

b. Texture

c. Light: Sources and shadows.

d. Color 
e. Sound, especially sound created by and from the architecture.

Spatial relationship. Bogart defined spatial relationship as "the distance between two things onstage, especially one body to another; one body (or bodies) to a group of bodies; the body to architecture" (p. 11). Understanding spatial relationship is important for actors to see that they are not working alone onstage, or that their physical choices do not have any relationship to those around them.

Topography. Topography is the landscape, the floor pattern, or the design actors create in movement through space. Understanding topography is understanding the "traffic pattern" that actors make as they move through the acting space. Bogart imagined actors having red paint on their feet. When the performance is finished, the red paint marks reveal the topography. The routes that actors use to move around the space tell a story.

Shape. Bogart defined shape as "the contour or line the body (or bodies) makes in space" (Bogart, 2005, p. 9). All shape can be broken down into lines, curves, or a combination of lines and curves. In addition, shape can be viewed as either stationary or moving through space. Shape can also take three different forms: the body in space, the body in relationship to architecture, and the body in relationship to other bodies making a shape.

Gesture. Gesture was defined by Bogart as "a movement involving a part or parts of the body; gesture is a shape with beginning, middle, and end" (p. 52). Gesture is created by any part of the body, including combinations of parts. In addition, gesture is broken down into:

a. Behavioral gesture: a gesture which belongs to the concrete, physical world of human behavior as we observe it in our everyday reality.

b. Expressive gesture: a gesture that expresses an inner state, an emotion, a desire, an ideal or a value. It is abstract and symbolic rather than representational. 
Viewpoints: Liberatory Ensemble and Character

These nine individual viewpoints combine to help actors and directors define the physical elements that an audience sees on stage. When broken down into specific viewpoints, directors and actors can more clearly tell the story they wish to tell and create the feelings they want the audience to experience. It's important that directors and students understand that these nine specific viewpoints need to be understood individually, but that they also need to be examined in combinations and as a whole. When students are allowed to make these discoveries, they may also begin to take more responsibility for their physical choices on stage. Directors can solve many actor problems through Viewpoints.

\section{Creative Play}

Much of Viewpoints is dependent on the act of creative play, an environment where actors are given free rein to move, interact, and explore physicality, story, and text. A number of people have written about this process. Brook (1996) is a strong advocate of creative play in the elimination of what he calls "deadly theatre," theatre which is merely repetitive and commercial and has no real productive or therapeutic benefit for actor or audience. In fairness, theatre does not have to be therapeutic, and in many ways theatre can be effective simply as a recreational tool or a mode of entertainment. Brook is, instead, castigating theatre which is done by rote, where neither actor nor director has much interest in the product beyond financial profit. According to Brook, "fun continually needs a new electric charge: fun for fun's sake is not impossible, but seldom enough. Frivolity can be its charge: high spirits can make a good current, but all the time the batteries have to be replenished: new faces, new ideas have to be found" ( $p$. 70). Campbell (2008), in his study of the creation of story, archetype, and hero, talked about blunder. Blunder is a "mistake" in a process that becomes integral to the direction the process eventually takes. Without blunders, which are constant in free, creative play, the process 
becomes stale and predictable, and nothing substantial is discovered. Blunders, which Campbell said are suppressed desires and conflicts, reveal choices that are unsuspected and often surprising, and the actor is often unable to explain why he or she touched something, said something, or moved in a particular way. An exciting element of creative play is that blunders and mistakes are not ignored; rather, they are incorporated into the creative process as if they were intentional all along.

Goffman's (1966) work with the social organization of gatherings shows the human creation of "involvement shields," behind which individuals can safely do the kinds of things that ordinarily result in negative actions. Actors can use characters as involvement shields. Through character, they can explore anger, frustration, self-doubt, and even evil. Creative play, when positively administered with students, gives them the opportunity to let these involvement shields down and participate in activities that would, in a more formal setting, seem silly, destructive, or unproductive.

Millman (1999) called creative play "movement play" and claimed that for young children - even infants - movement play provides their vital bodies with exercise, stimulation, and a means of discovering their relationship to natural laws. Movement play has four objectives for children:

1. To feel good about their bodies.

2. To experience success early on by beginning with relatively easy tasks.

3. To enjoy active movement through accomplishment.

4. To develop confidence by completing tasks. (Millman, 1999, p. 33)

This focus on process, rather than result, has significance in the development of children's learning capabilities and social interaction. Nachmanovitch (1991) used the German 
word funktionslust, which means the pleasure of doing, or producing an effect, as distinct from the pleasure of attaining the effect or having something. Play should be intrinsically satisfying, and is its own reward. Rimer and Masekazu (1984) wrote that role play should not be taught so much as allowed. When there is too much restriction, too much focus on rules, too much admonition, the child loses interest in the activity. Viewpoints, when properly introduced, can give students funktionslust; they are able to play, have fun, and be productive through safe and creative physical exploration. But they must be allowed to role play, to improvise, and to create without too many rules and boundaries, and they absolutely cannot do any of this if a director or teacher is consistently controlling their choices.

The goal of creative play is to create a sense of reality; students are enjoying the role play so much that they are not concerned with performance-everything is a natural, realistic delivery. Krasner (2006) looks at the theory, practice and application of the Stanislavski method of acting, which focuses inherently on finding what is "real" in performance. He found that “encouraged by unimaginative directors and teachers, actors often seek the easy path, using little more than superficialities to achieve treacle feelings" (Krasner, 2006, p. 28). Most directors find that Krasner's point is fundamentally true: actors, and particularly student actors, will often take the path of least resistance if they are not challenged and encouraged to create. They settle into characters and stumble into choices rather than taking ownership and pride in their work. Stanislavski's method was created to help actors connect in real, emotional and psychological ways to their characters, but this can never be achieved unless actors are given the proper encouragement and opportunities to explore this. Barry (1997) found that humans are consistently looking at what is real, to the point that they are able to quickly determine if something is genuine or not. This applies to performance as well. They are quick to understand if 
a performer has an honest connection to his or her work. Our emotional state, our mindset at the time, and our prior experience all contribute to this.

\section{Symbolic Interactionism}

Sociologist Herbert Blumer's (1986) phenomenological approach, known as symbolic interactionism, has a cohesive relationship with the methodology of Viewpoints. Symbolic interactionism rests on three basic premises:

1. Human beings act toward things on the basis of the meanings that the things have for them.

2. The meaning of such things is derived from, or arises out of, the social interaction that one has with one's fellows.

3. These meanings are handled in, and modified through, an interpretative process used by the person in dealing with the things he encounters. (Blumer, 1986, p. 2)

Viewpoints relies on similar premises. First of all, Viewpoints exercises create pictures, stories, and relationships all through physical expression. When students are interacting in the Viewpoints exercises, they are doing so in a spontaneous and free-flowing manner. The students participating in the exercise will immediately create relationships determined by something as simple as spatial relationship; the distance between actors, and how that distance increases or decreases, tells these actors what relationship is being created. Likewise, this visual relationship is coded by the audience; they may even create a relationship or story about the exercise completely different from the actors. They are responding and creating meaning by something as simple as distance. Each of the nine Viewpoints creates movement for meaning, and human beings use this meaning to tell stories and create environments for learning and expression. 
When these movements are psychologically coded by either actor or audience, the way the actors then associate and interact with each other onstage will create more social codes that the audience will interpret. They will see pacing and speed, which Viewpoints calls Tempo, as another determinant of meaning. They begin to assign emotion to these movements - speed becomes feeling. This is a social contract between actor and audience; the actor offers portrayal, but the audience is free to create social meaning. One of the strongest arguments for theatre as education is that the audience participates often unwittingly and is given license to create meaning without being aware that it is happening.

Naturally, not all audiences will assign the same meaning or codification to the same physical choice. Viewpoints recognizes that audiences will find their own interpretation and that this interpretation may be completely different from that of the actor or, ultimately, the director. This is allowable and even encouraged. Once the meaning has been assigned and coded in the audience member's mind, there is then the opportunity to discuss what has been seen and understood, if the educational environment has been created effectively. The rehearsal hall, when directors allow liberal physical exploration, can thus be an environment for discussion and learning, where student actors are free to improvise without words and student audience members are able to comment, discuss, and converse about what they have seen and experienced.

\section{Mead's Social Psychology as the Foundation for Viewpoints}

Viewpoints is based on the notion that humans are constantly making social connections. When one person acts, another person reacts. When a group of people does something, another group of people may observe and create meaning from it. This is not just relevant to the stage; these kinds of social interactions happen to human beings on a constant basis. In the theatre, 
however, these human connections and interpretations are amplified, and actors and audiences share an interactive relationship. Viewpoints helps to codify and understand the meanings behind this relationship, helping actors understand both conscious and unconscious choices and clues. Symbolic interactionism, as defined by Griffin (2012), "refers to the patterns of communication, interpretation and adjustment between individuals. Both the verbal and nonverbal responses that a listener then delivers are similarly constructed in expectation of how the original speaker will react. The ongoing process is like the game of charades; only it's a full-fledged conversation" ( $p$. 212).

Background. George Herbert Mead (1967), the American philosopher, psychologist, and sociologist, examined group life and found that consciousness (the social and cognitive discoveries human beings make about their world) emerged from human group life. Humans respond to pre-existing and self-constituted objects, which creates their behavior. The content of Mead's Social Psychology can be broken into the following categories:

1. Society

2. The Self
a. The preparatory stage
b. The play stage
c. The game stage

3. The Mind

4. The Act (Manis \& Meltzer, 1967, pp. 5-24)

For Mead, understanding human nature was possible by understanding how humans interact in society. Humans have needs and intentions, and they pursue these intentions within the realms of society. The self, which represents each human, achieves his or her intentions 
through a series of tactics. In the preparatory stage, the self "imitates" what it sees others do. In the play stage, the self "interacts" within society, participating and creating codes of understanding to make sense of its world. In the game stage, the self has mastered how to pursue intentions and can play, create, and understand societal rules and boundaries. Much of this process happens within the mind of the self, as humans endeavor to understand their world and how they function in it. Once they have completed that process they may be ready to act. The act begins with an impulse, which is strengthened through tactics and objectives, until the intention is realized.

Hewitt (2000) broke symbolic interactionism into five main principles:

1. The task of social psychology is to account for the formation and varieties of human social conduct.

2. Human conduct depends on the creation and maintenance of meaning.

3. Human conduct is self-referential.

4. People form conduct as they interact with one another.

5. Society and culture shape and constrain conduct, but they are also the products of conduct.

Connections to theatre. Theatre functions along these lines. Actors create and maintain social conduct on a stage, which is codified and understood by an audience. The audience attaches meaning to what they see on stage; when characters make choices, they draw conclusions. This happens whether the choices are deliberate or not. The audience, then, refers these choices to themselves. Would they act the same way? Do they agree with what the characters are doing? How does this make them feel? As they watch these actors interact with 
each other, or interact with themselves as an audience, they understand more clearly why they conduct themselves the way they do.

Each of these central matters can be explicitly explored in Viewpoints exercises and developed for a performance. Where Mead saw the human being as a figurative actor, a "character" who lives life offstage rather than on, Viewpoints sees this literally. The human is the actor, and each experience is created by, and for, the actor to develop. Mead implies that the actor is an object to himself; the actor uses himself to indicate and designate his wants, feelings, and needs. The meanings that symbolic interactionism focus on do not have to be social; they can also be solitary. The actor can be alone in his or her expression, and the coding of meaning will still happen. This interpretation can happen in a solitary way as well, or the actions of one actor can be interpreted by an entire audience. Further, while Viewpoints places a major focus on ensemble work and actor interaction, actors alone on stage may also do great work and make solid discoveries.

Mead points out that there are inherent differences in the interactions between human and non-human beings. Most animals respond instinctively to each other because they are physiologically designed to respond in certain ways. They can be trained to follow commands, but ultimately they repeat certain behaviors without change in pattern. Humans are different. Humans reason through interaction, assigning intention to their interactions. They do not automatically respond to most interactions with others, but base their responses on the intentions of the person to whom they are responding. Once that intention has been determined, the human will respond accordingly. Because of this, humans are able to create behaviors that are appropriate for most situations. They can also learn to understand the behavior of others more fully. 
In a rehearsal setting, actors are encouraged to find the same appropriate responses. Audiences can inherently sense when a physical or vocal choice onstage is incorrect; they may not be able to verbalize why something feels wrong, but they can definitely feel it. Often this is because the actor has failed to train himself or herself to respond in the moment, as human beings do in real life. Their actions become pre-planned onstage, in much the same way as insects repeat endlessly the same pre-planned patterns of behavior. Viewpoints exercises, because they happen in the moment and are rooted in impulse and response, encourage actors to break out of these patterns of monotony and instead find choices that are alive and honest.

An example of this social interaction is Gesture, which is one of the nine Viewpoints. Because human beings are trained to seek intention in gesture, each physical movement of the body carries meaning and relevance. The same holds true onstage. Deliberate and, even more so, undeliberate movement holds meaning for an audience. Why did the actor move then? Why are her hands shaking? Why do they smile when they look at one another? The audience is constantly assigning meaning to gestures and then watching to see if the actors understand the intention of the gestures by their responses. If the impulses and responses onstage don't feel genuine to the audience, they may feel a sense of detachment from the production. This is another connection actors have to audience; they are both responsible for the interpretations of these gestures. To quote Mead,

Unless interacting individuals interpret gestures similarly, unless they fill out the imagined portion in the same way, there can be no cooperative action. This is another way of saying what has by now become a truism in sociology and social psychology: Human society rests upon a basis of consensus, i.e., the sharing of 
meanings in the form of common understandings and expectations. (Manis \& Meltzer, 1967, p. 17)

Viewpoints, with its emphasis on ensemble, creates an environment where groups are encouraged to act spontaneously and with absolute freedom, but it also recognizes that the interpretation of these physical choices is not without meaning; human beings create and respond to their own gestures innately. When they respond to others' gestures, however, the act is a social one. Having a moment of consensus, where the actors have time to vocally process and comprehend their experience, can be very cathartic and encouraging for young actors. It becomes a social act, where students discuss and interchange their feelings, discoveries, and frustrations.

Genesis of self and character. Mead suggests, however, that human beings respond to others in the same way that they respond to themselves. The self is of primary importance. They treat others the way they treat themselves and hold others to the same expectations. Theatre is one way to help actors see beyond themselves, or at least see themselves more clearly through the eyes of others. This can be incredibly eye opening for many student actors, as they may have been trained to focus only on their own performance, their own choices, and their own objectives onstage. They are discovering a world beyond themselves. Mead calls this the "genesis of self" and offers three stages of genesis which student actors often mirror in their training.

Preparatory stage. In this stage human beings merely mimic. This is typical in babies and toddlers, who mimic what they see adults doing. They may not have any understanding of what they are doing, and their choices may be physical without meaning. Likewise, novice actors find mimicry to be helpful as they create roles. They may decide to copy another actor's performance completely, in voice, in body, and in intention. These performances do not, generally, have any relevance or life to them. 
Play stage. In this stage of human development a child begins to role play and finds that the joy of role play comes from his or her own reaction to the character he or she is playing. For example, a child may pretend to be a teacher and relish the ability to make the teacher strict and angry. The child can respond to the teacher by becoming the teacher. For actors, this step is important as they seek to create a role. This is a much deeper relationship to character than the preparatory stage, which was mere mimicry. The actors are now connecting themselves to the character and creating responses to how they are choosing to play it. It is a slightly more mature level of performance, though still lacking distinct honesty and life.

Game stage. In this stage the child learns that it is not enough to just "be" the teacher. The teacher must be several things: a leader, a follower, a comforter, a disciplinarian, a spouse, a parent, and any number of other social roles. The child learns that he must create consistent actions that flow smoothly between these roles, which in the theatre is the difference between a two-dimensional performance and a three-dimensional one. Actors who reach this "completing" stage understand that they are playing real people who play many roles but who can also vary their levels of energy and intensity as they shift among these roles. They have learned that by simply listening and responding honestly to other actors onstage they can create a consistently genuine character. (Manis \& Meltzer, 1967, pp. 10-11)

Each of these stages is mirrored in the process that an actor might go through in creating a character. The genesis of self, then, mirrors the genesis of character. Actors may begin their process of character development by mimicking what they've seen on television, film, or from other actors. Once they feel comfortable with this, they may push themselves to ask more questions, make more choices, and try to explore a character through play. By the game stage, 
the actor has become adept at role play and has connected with the character in a much more personal, psychological way. They "are" that character.

The importance of social psychology in theatre. Mead sees mind as the self in action, meaning that communication between humans creates mental responses, as long as symbols are being created and deciphered. But there is also a sense of adjustment; humans adjust their responses according to the stimuli they are offered. Humans are constantly adjusting to change around them, seeking for the appropriateness in each situation. Attention is selective: humans focus on what they most need to focus on and often choose to ignore the rest. In acting terminology, this is referred to as "objective." The character focuses on what it wants to achieve in a scene, and this focus is the dominant effort. If, however, there is an obstacle in the way of the objective, or a change in the characters' needs, there will be an adjustment as well. This selectivity in attention is as true on stage as it is in real life. There is a tactile planning process in the human mind that dictates how a human should act when presented with stimuli. It may be an extremely quick process, feeling almost instantaneous to the individual, but there is still some measure of delayed organization in response.

Again, Viewpoints works to help actors respond in the moment, but also to understand why they responded in certain ways. These exercises free students from overthinking or prethinking behavior; instead they learn that when something happens onstage they can respond to it rationally and with purpose. They also learn that there is logistic, tactical sense to their responses, even if they feel immediate or spontaneous. This type of behavior, when translated into performance, gives both the actor and the audience a sense of immediacy and reality. Mind, according to Mead, is symbolic behavior. Theatrical performance is meant to be symbolic in the same way. 


\section{Method}

Viewpoints has been well documented to be effective in the professional field, and the idea of a liberatory rehearsal is not new, but the combination of these two-using Viewpoints to create a student liberatory rehearsal — has not been fully researched. Using Herbert Blumer's (1986) phenomenological approach known as symbolic interactionism and George Herbert Mead's (1967) social psychology, this research, composed of three major case studies, clinical interviews with students and professors, and autoethnography, explored how Viewpoints creates the ideal collaborative studio environment.

The research questions were explored through various methods of symbolic interactionism (patterns of communication, interpretation, and adjustment between individuals) and both autoethnography and student/professor feedback, via interviews. These asynchronous, standard open-ended interviews comprise the majority of the data collection involved. These were done online because many of the subjects were former college students who had left the state but were willing to participate via email. This also reduced issues of nonverbal behavior that often occurs in face-to-face interaction, in addition to the following benefits of standard open-ended questions:

1. Avoid long explanations of the study.

2. Stay close to the study introduction, sequence of questions, and question wording.

3. Avoid other people interrupting or challenging the interview.

4. Keep free of offering my own opinions, agreements, or disagreements.

5. Accept the answers without offering interpretation while an answer is being given.

6. Avoid improvisation or word changes to the questions being asked. (Denzin \& Lincoln, 2011) 
Viewpoints: Liberatory Ensemble and Character

In addition to these online responses, past fieldwork and observations of current events and situations, with notes and description, are included as data.

\section{Findings and Discussion}

If Viewpoints is successfully able to create a liberatory rehearsal period, it would be reflected in the responses from both the director and the actors in a production where it was utilized. My purpose in introducing the following case studies is to show how effective Viewpoints is in actual practice and whether the Viewpoints can create a "liberatory" environment that correlates with Freire's (2000) liberatory system of educational practice. In the three productions examined in this study, directors who chose to use Viewpoints found that their actors were open and honest and that they contributed to rehearsals in vital ways. Actors who used Viewpoints found that their sharpest theatrical impulses were given an avenue of expression and that they felt a sense of ownership in the resulting performance. They also gained an important education in teamwork and creative collaboration, which could benefit them in whatever professional field they eventually enter.

Ultimately my findings reflect the notion that this effectiveness is entirely dependent on the following:

1. How Viewpoints was introduced and explained.

2. How much freedom the students were given to explore in rehearsal.

3. How the Viewpoints exercises were connected to the students' final performance work.

Friere's (2000) idea of "liberatory pedagogy" is rooted in the notion that students have to be given the freedom to explore and the encouragement to create without restriction. While this may terrify some directors, the following case studies show that Viewpoints can be, and often is, 
Viewpoints: Liberatory Ensemble and Character

one of the most effective ways to create character, tell a story, and provide a fulfilling experience for students.

\section{Case Study: Romeo and Juliet}

Romeo and Juliet was performed by Brigham Young University students in the Pardoe Theatre on BYU campus November $11^{\text {th }}-$ December $4^{\text {th }}, 2010$. It was directed, by assignment, by Dr. Megan Sanborn Jones, an Associate Professor of Theatre. Sanborn Jones, who has had formal training in Viewpoints, decided to use the exercises in the rehearsal period of her production.

Introduction of Viewpoints to students. Sanborn Jones used 30-60 minutes of each rehearsal period to do physical Viewpoints exercises with her cast, focusing on a specific Viewpoint or a combination of them. Following the exercises, she talked with the cast about their experiences and encouraged them to share their discoveries. In doing so, she was able to create, within the rehearsal hall, an effective liberatory studio classroom where students could participate and take ownership of their work rather than being controlled by a traditional director who thinks, talks, disciplines, and chooses for them. This relates directly to Freire's (2000) notion of the banking system, where a teacher merely lectures, metes out information, and expects silence and obedience from students. This kind of liberatory process is unusual for most directors, who generally want to rehearse immediately with the text and create the blocking, or staging, of a piece. Viewpoints eschews the traditional format of direction; it requires that directors allow actors to make their own choices and incorporate them into their performances. In a live interview with the director in February 2012, using qualitative standard open-ended questions, I learned that introducing Viewpoints initially was difficult for Sanborn Jones; she realized quickly that she would have an uphill battle: 
I was aware that most of my students didn't know anything at all about Viewpoints. I have taken multiple workshops from members of the SITI company. I have read all of Anne Bogart's works. I have practiced using Viewpoints in directing for over 10 years. I teach workshops in Viewpoints to others. I attended a workshop that Anne Bogart herself facilitated, and was pleased to see that the workshops I've developed are very similar. But I knew that these were new concepts for them, and that they might be resistant to a form of rehearsal at odds with what they were used to. I knew how much Viewpoints could help them, but I also knew that these were uncharted waters.

Sanborn Jones was working with a cast of students whose experience with Viewpoints ranged from those who had never heard the term to those who had attended workshops and were familiar with all of the elements. In asynchronous interviews via email with four of the cast members, Angela, Ben, Mary, and Andrew (not their real names), all theatre majors at BYU, I learned that these students had differing previous experience with Viewpoints. Angela, a graduate student in theatre history from Caldwell, Idaho, had already received some training in Viewpoints before working with Sanborn Jones on Romeo and Juliet. She had taken a contemporary performance class at BYU that contained a unit in movement-based theatre. According to Angela, this class spent two weeks working with Viewpoints, and Angela chose to use Viewpoints for a final project in the class. Ben, a theatre education major from Orem, Utah, had not used Viewpoints before, though he had heard of the technique. Mary, a theatre arts studies major from Beijing, China, had used Viewpoints only once, in a previous audition at the university. Andrew, a doctoral student in theatre and performance studies from Orange Park, 
Viewpoints: Liberatory Ensemble and Character

Florida, had read an article on Anne Bogart and had learned a little about Viewpoints through a class lecture.

Freedom to explore. Sanborn Jones explained how she used Viewpoints to help the actors create character by exploring each Viewpoint individually, and then used the students' physical responses to create character and tell the story:

The cast used Viewpoints to create movement pieces that told the backstory to our version of Romeo and Juliet, set in New York's gilded age. These pieces required the cast to know their character, their character's motivations, and the way in which the character moved through the environment and interacted with others. Angela, who also choreographed Romeo and Juliet, commented on the growth of the cast through Viewpoints.

I do think that because we Viewpointed with so many of the other scenes, and because I was there and working with everyone, I had a connection that I wouldn't have had. I was able to connect emotionally and physically because I was able to grow with the cast as they discovered their characters in rehearsals. It also helped me become more emotionally connected to the choreography that I created and that I was performing with.

Ben felt initially that Viewpoints was successful in helping him create his character. He related, "Viewpoints helped me explore my character from an external source to better feed my internal source. It was great to work 'outside in' to create a character very different and abstract to myself." Working "from the outside in" is a term many actors use which means that they may create a character physically, rather than emotionally or internally; exploring a character's walk, 
Viewpoints: Liberatory Ensemble and Character

mannerisms, and dialect rather than his emotional memories or feelings and motivations in a scene.

Mary didn't necessarily respond to Viewpoints as a character development technique, but she did seem to connect to it physically. Her experience with Viewpoints was less about creating a character and more about finding comfort to move onstage. This is an added benefit of the Viewpoints exercises. Several of the students mentioned that Viewpoints freed them up to simply move onstage, an issue that a director needs to recognize. Many actors can't move into the realm of connection and creation until they are fully capable to simply be on stage. Mary, for example, found this to be true.

I found Viewpointing to be really helpful in establishing the physicality of my relationships with other characters. It helped me to explore space and its meaning. I also found it to be very freeing. Romeo and Juliet was done in a very stylized way and I think that without Viewpointing I would not have felt comfortable on stage. Viewpointing helped to ground my physicality.

Andrew also seemed to connect to his character physically through Viewpoints. But he also found it a challenge to create a character out of a figure in the play who merely narrates. His response to Viewpoints seemed to be rooted in his personal response to it; his discoveries were less about character and more about himself as an actor.

My character was odd because so much more of what I did was narrate; I only had three scenes in which I interacted with the characters in a non-narrating capacity. So much more of my character was determined by a performance of an historical figure whose autobiography I had read and used to create our production's backstory. But I think use of Viewpoints helped me determined ways that I 
Viewpoints: Liberatory Ensemble and Character

carried myself and how I presented myself. Early in the rehearsal process I did a lot of the Viewpoint exercises and initial stage pictures. I think this facilitated my interaction with the other characters in the world of the play-how my character Peter would have responded to members of other families or his own.

Viewpointing really helped with my character in that sort of relational awareness that we focused on with the kinesthetic awareness and shifts.

Andrew's discovery of how to "carry" and "present" himself reinforces the idea that a large part of Viewpoints is designated to simply help actors move. While it is an effective way to help them interact and connect, it also helps actors to get to a point where they are physically freer to walk, stand, or dance. And frequently theatre educators forget that these physical tasks are obstacles for many young actors who have not spent much time on stage.

Not all of the respondents felt that Viewpoints was consistently inspiring. For example, Ben expressed some reservations about how Sanborn Jones used the Viewpoints to create pictures and transitions and wanted a stronger emphasis on character creation.

I felt with Romeo and Juliet how the Viewpointing was structured was focused mainly on the transitions and a few scenes where I felt it should have been the basis of the whole show. By doing this I could have better created a character with more depth, honesty and groundedness. I also felt our show lacked relationships because we didn't use Viewpointing activities to help us in this task.

Ben's responses to Viewpoints seem to be rooted in the fact that he never made the connection between process and product. He viewed the exercises as a way to help transition from scene to scene, but didn't seem to understand how the exercises could have helped him 
create a character, form relationships with other actors and characters, or better understand social conduct.

Sanborn Jones focused on duration, shape, and gesture the most because she wanted to create interesting stage pictures, as well as scene transitions. While the scene transitions that Ben mentioned were a part of her Viewpoints usage, she also saw a deeper use for the exercises; they created an ensemble, with a common vocabulary, that wanted to work together.

I generally always go to Viewpoints as a place to start with my directing. I find that it provides a unified vocabulary for the cast, and that the workshopping process creates an ensemble feel to the show. Additionally, I felt that Viewpointing full sections of Romeo and Juliet would provide a physical basis for the production that would help tell the story in a powerful way. And it made the scene changes deliciously lovely.

While it would be difficult for students to remember all of the Viewpoints used in the rehearsal process, when they were asked which individual Viewpoints they most remember using, Andrew, Angela, and Mary remember using kinesthetic response; Andrew and Ben remember using topography; Andrew, Angela, Mary, and Ben remember using shape; Andrew, Angela, and Ben remember using gesture; Andrew, Angela, and Mary remember using tempo; Andrew remembers using repetition; and Angela and Ben remember using spatial relationship. None of the students recall working with duration or architecture, though this is not to imply that Sanborn Jones did not introduce them in rehearsal.

When asked which, if any, of the Viewpoints had the most impact on their character, the students had varied responses. Ben found that topography and special relationship helped the cast move their production effortlessly from the rehearsal hall to the performance space. Mary felt 
that tempo impacted her performance the most, and said that tempo "felt like it related a lot to my emotions and that it was an easy way for me to express my emotions through movement without feeling too strange or abstract." Angela seemed to have an intense experience with kinesthetic response.

I think that the Viewpoint that helped us the most in developing the piece was kinesthetic response. I can't express enough about how Romeo and Juliet was one of my favorite experiences in the theatre, and that was because of the process that we had in rehearsals and the bonds that were created in the cast. Using kinesthetic response and repetition in warm-ups really helped to create that bond that so many of us in the cast experienced.

Kinesthetic response, the immediate, spontaneous reaction to something someone says or does, is at the heart of Viewpoints. Viewpoints works along the tightrope of cause and effect; when a choice is made, another choice must be made. This can be exhilarating, but only if actors are prepared to make instinctual, spontaneous responses to each other. Viewpoints works only if actors are able to work impulsively and without pre-meditation. Angela's reference to kinesthetic response creating a "bond" underscores the idea that she began to trust and appreciate her cast more because she was allowed to instinctively interact with them.

Effects on performance. The students were then asked how they felt Viewpoints informed and impacted their final performance, and their answers varied between mildly enthusiastic and wholeheartedly effusive. Andrew, who had almost no previous acting experience, seemed to find the Viewpoints process a little overwhelming as he tried to understand the world of theatre in general. His response reinforces the important idea that 
educators have to understand: students may not be ready to create a character or connect to other actors until they are physically comfortable on the stage to begin with.

That is not to say it did not affect my performance. Part of the issue is that I had never acted in anything. Never took an acting class in college or high school. I did a ten- minute scene in an introduction to theater class and a scene from a play in a talent show, but that was about it. So I did not have anything to compare what I was doing to anything else. Dr. Jones had to occasionally give me notes about making less overtly abstract shapes; but then I eventually was not making any shapes as I did not move around the stage much. I think because I had no other form of training and because our play was emphasizing the many different social relationships that were impacting and informing the world of the play, Viewpoints did let me think about how I was relational to other characters. That helped build a great camaraderie and rivalry amongst our cast. I feel like it was not so much a matter of affecting my performance directly as much as affecting it by establishing my performance within a community of forces.

Angela found that Viewpoints made her feel like she was an integral part of the production, rather than a bit-part player.

My performance was affected by Viewpoints in that it was one of the only ways that I could connect to the piece. I didn't have any lines, and I wasn't in many spoken scenes. I had the chance to be highlighted in the movement-based scenes and in the choreographed dance sequences. When it came to a spoken scene that I was in, I wouldn't normally have felt like I belonged in that scene because I hadn't grown with the story, had an arc, or had any emotional connection to what 
was happening. I do think that because we viewpointed with so many of the other scenes, and because I was there and working with everyone, I had a connection that I wouldn't have had. I was able to connect emotionally and physically because I was able to grow with the cast as they discovered their characters in rehearsals. It also helped me become more emotionally connected to the choreography that I created and that I was performing with.

Angela seemed to realize that her presence on stage was more than just to fill space. Sanborn Jones, through Viewpoints exercises, effectively helped Angela realize that every character on stage has a purpose and a reason to be there. This can be incredibly helpful to new actors who have smaller or more supporting roles. Viewpoints allows actors to see that their actions, whether they are integral to the story, have meaning, effect, and import.

Ben's response was somewhat perfunctory. He felt that Viewpoints helped him with “energy, purpose, commitment, and projection of energy." He also felt that this helped both him and the audience understand the world and the meaning of the play. Ben didn't seem particularly effusive about how Viewpoints affected his own performance, but as a director of future projects, he seemed to have a keen interest on using Viewpoints again.

I actually plan on directing with Viewpoints as my main source. I would start out my rehearsals with Viewpointing activities. Painting the floor with paint has really helped me in past work develop a character, make my character threedimensional, and become more vulnerable. I would use Viewpoints in transitions again, for it was very successful, yet I would use Viewpoints in all scenes, whether we perform the viewpoint in the actual performance or use it as a springboard for character development, relationship building, and/or cast unity. 
Viewpoints: Liberatory Ensemble and Character

Mary experienced the freedom from pre-planning as found in Mead's social psychology, wherein her acting choices defied monotony and became alive. She expressed her experience as follows:

I feel like sometimes we get so caught up in the honesty of acting or trying to be "real" that we forget to explore and open ourselves up to new possibilities, new ways of moving and being. I loved that it forced me to get out of my comfort zone and that by the end of the rehearsal process it was part of my comfort zone.

Conclusions. Sanborn Jones seemed to effectively use Viewpoints in her rehearsal process. There were some great connections made to both character and self, and the students reported a greater sense of cast unison and ensemble. They also commented on the clarity of the "pictures" and storytelling that the exercises helped to create. But there was also some indication that Viewpoints could have been more effectively introduced, more cohesively explained, and a better connection established between the rehearsal exercises and the final performance. Throughout the responses, however, there was a sense of liberatory rehearsal happening: actors were exploring, playing, and creating and an encouraging environment that Sanborn Jones established and promoted. Because of this, she was able to avoid a "deadly theatre" version of Romeo and Juliet, a 400-year-old play that can easily fall into the trap of repetition and monotony. Her efforts, by creating and echoing the teaching environment Freire (2000) proposed, were successful in providing her students with a valuable experience and her audience an innovative and thoughtful production.

The Romeo and Juliet experience Sanborn Jones provided, by using Viewpoints in rehearsal, encouraged her students through Mead's (1967) “genesis of character” process by using the following methods: 
1. Creating movement and physical choices that represented meaning, as evidenced by Mary, who claimed that Viewpoints "related a lot to my emotions" and found the theory "an easy way for me to express my emotions through movement without feeling too strange or abstract.”

2. Linking these physical choices to character types, as evidenced by Ben, who felt that "Viewpoints helped me explore my character from an external source to better feed my internal source" and was excited to work physically rather than internally "to create a character very different and abstract to myself."

3. Adding completeness to character through honest interaction, reducing flat or "stock" character choices, as also evidenced by Ben, who claimed that Viewpoints helped him “develop a character, make my character three-dimensional, and become more vulnerable."

Sanborn Jones was mostly successful in her usage of Viewpoints in rehearsal, a fact each student bore witness to. She created a studio environment, where students were, in essence, liberated from the traditional controlling, top-down patterns of direction they may have been accustomed to. In the future, however, she may want to take more time introducing the meaning and advantages of Viewpoints for students like Andrew, who had very little stage experience prior to Romeo and Juliet. She may also want to help students like Angela understand that Viewpoints is effective for smaller or secondary roles, and is not meant only for leading roles. And she may consider helping students like Ben understand that Viewpoints is not only for pictures or transitions, but can be used throughout the entirety of the production. 


\section{Case Study: Godspell}

In a second case study, T. Anthony Marotta, an Assistant Professor of Theatre at Southern Utah University, used Viewpoints as a foundation for his production of the musical Godspell, which played April $14^{\text {th }}-18^{\text {th }}, 2011$, in SUU's Auditorium Theatre. Marotta had previously trained directly with Anne Bogart and knew the benefits of Viewpoints would have for his production. In a live interview using qualitative standard open-ended questions, Marotta claimed that he wanted to use Viewpoints expressly because he wanted his student actors to use their movement training in their work, to develop a strong ensemble, and to achieve strong characters and clear storytelling despite a brief three-week rehearsal process.

Integration of this technique gave the students and me an opportunity to apply lessons from class, and allowed me to go more deeply into a common and creative rehearsal technique that enhances their training as actors and directors. With the entire cast on stage for the entire show, and a range of very personal themes like religion, community, communication and personal choice, I chose Viewpoints as a catalyst and bridge for performers to work together more easily and respectfully, communicate more freely, and connect in very personal ways to the storytelling, each other and the audience. With 13 actors on stage for the entire piece, and few character or relationship choices written into script, Viewpoints become a method for fleshing out characters and their relationships to each other as well as equipping the performers, with less reliance on me, to create active and engaging stage images and movement.

Introduction of Viewpoints to students. Marotta decided to implement a three-day Viewpoints introductory session before beginning rehearsals. In this session, Marotta let his 
students move and interact with each other, carefully helping them understand, through periodic group discussion, their physical choices and kinesthetic interactions. This was followed by a two-week Viewpoints intensive once rehearsals had officially begun.

Marotta had a challenge introducing Viewpoints considering that the majority of his university student cast, including Brett, Alexander, Maclean, and Katrina (not their real names) had never worked with Viewpoints before, and Brett had never even heard of them. In asynchronous interviews via email I learned that many of Marotta's cast were unfamiliar with Viewpoints and had never been exposed to them. Alexander was one of the few students who claimed to have been introduced to Viewpoints prior to Godspell, as a student in Marotta's stage movement class at SUU.

Freedom to explore. In introducing these new concepts to student actors, Marotta found that he needed to prepare them for a different kind of rehearsal than they were used to.

This was the first opportunity I have had to use Viewpoints as a Director and within a musical theatre piece. I haven't had a lot of opportunity to go deep into the process, especially with previously scripted material. I made an agreement with students that this process would be research and exploration that we would all learn from. We were very relaxed and playful about it. With such a truly malleable script the benefits, even if minor, could contribute on many levels. And did.

Marotta wanted to find ways to help his students make reasoned decisions about their characters and then find ways to physicalize these choices into action through Viewpoints. Since the script text and song lyrics were sometimes difficult for the cast to connect to, Marotta hoped that Viewpoints would help these actors fill in the gaps by creating relationships and clarifying 
their storytelling. He introduced the specific Viewpoints individually and then helped the students discover how all nine Viewpoints linked and related to each other, and found that Viewpoints was effective in expanding relationships, discovering character, and creating stage movement and ideas. In addition, Marotta found that he was developing more than a production-he was developing a community.

It opened up a difficult script, empowering the performers and me to tell a story in a very personal, physical way that was inclusive of the audience. It was fresh and alive. One of the strong themes of the play is "community." This very intensive ensemble work developed an expressive and close community of performers, giving them something extraordinary to express and share on stage. To make sure everyone was on the same page, we started the rehearsal process with a three-day Viewpoints workshop. For a condensed three-week rehearsal, this was an investment that truly paid off. This workshop began from a non-specific Viewpoints exploration but continually moved toward more themes, stories, images and action that related specifically to our play, its world and characters. This workshop not only provided the foundation vocabulary of movement and storytelling for the rest of the rehearsal process and performance, but gave the ensemble a common and profound shared experience. It also set in motion the idea that characters, story, and image come from their own creativity and personal experiences, and not primarily from the director, and should be physical. It gave them much needed freedom and ownership to play. It also set the tone that everything we do needs to focus on our common goal, which is to tell the story of the play. 
Viewpoints: Liberatory Ensemble and Character

Katrina, a political science major from Vernal, Utah, was enthusiastic about the way Viewpoints assisted her in creating her character, claiming that she "felt so basely connected to my character and all the others in the show by just throwing away the text and feeling out the relationships with my whole body." This was echoed by Alexander, a musical theatre major from Henderson, Nevada, who felt that "Viewpoints really helped create an environment of play and experimentation where we could discover not only our characters, but our relationships as well."

Brett, a ballet major from Tridell, Utah, found that Viewpoints made him feel "like I had discovered the world that my character lived in more fully than I ever have before." Only Maclean, a theatre performance major from Cedar City, Utah, was slightly hesitant, expressing that Viewpoints worked better as an ensemble-building tool than a specific character definition, and felt that his “character evolved with the ensemble as a whole. I didn't sit down and say 'this is who I want my character to be.' It changed and was molded as our ensemble grew closer together."

When asked which specific Viewpoints helped them most in their process, Maclean, Katrina, and Alexander remembered shape; Maclean remembered tempo; Alexander remembered gesture; Maclean and Katrina remembered spatial relationship, and Alexander remembered architecture. None of the students mentioned remembering duration, kinesthetic response, repetition, or topography. In addition, some of the students seemed to have forgotten the names of each individual Viewpoint, instead using terms like "interactions," "spacing," "time," and "movements."

Katrina, a Directing major from Vernal, Utah, found Viewpoints to be helpful in creating, within the cast, a sense of community. She immediately noticed that Viewpoints was essential in 
creating this ensemble. For her, the show became less about her own personal efforts and more about the actions and choices of a team.

It brought us closer as a cast. I believe that there is nothing more crucial for an actor than his psyche. Viewpoints are a good way to connect fully in an easy way.

The whole cast has an assignment, a common goal, and specific instructions to care for one another. Since our Godspell was less about faith in God and more about faith in people and the power of community, Viewpoints turned out to be a substantial tool for the performers of Godspell.

Alexander found that one Viewpoint, spatial relationship, helped him better to connect to Judas, the character he played.

So often in a production like Godspell it's too easy to generalize (everybody is friends with everyone else, everybody loves Jesus, etc.). The Viewpoints work we did in rehearsal really helped me to find who in the group my character was closest to, who he struggled with, and those he had little connection with at all. In our production Judas was a constant negative pull throughout most of the first act. So we did one particularly memorable exercise where our character wanted to be close to Jesus but couldn't be close to Judas (or vice versa depending on the character). It was really helpful to have that tangible focus on that relationship and conflict, especially when Judas was close to Jesus and our characters had to decide what they would do.

This emphasis on spatial relationship was underscored by Alexander's relationship with the character of Jesus; he wanted to be close to Jesus but "couldn't be." The spatial relationship exercises helped him to connect the idea of physical connectivity with spiritual connectivity. 
Brett claimed that he would love to "learn more about Viewpoints in general" and seemed to appreciate having time set aside at the beginning of the process to create an ensemble before the stress of creating a production.

I loved that we all established who we were to each other before we started actually putting the show together. It made it so we understood who we all were in our community. I think that overall the performance was so much better because of the amount of time we spent working on Viewpoints.

Effects on performance. Maclean saw the cast make a journey from discomfort with Viewpoints to the necessity of them, reinforcing the notion that Viewpoints builds ensemble within the cast. But he also added that this sense of ensemble extended to the audience as well.

At first, I felt our cast was very hesitant. We had a five-week rehearsal frame, and two weeks was spent doing intense Viewpoints rehearsals. Typically, that valuable time would have been spent setting the show, music rehearsals, etc. But the very last week, we saw the difference. We were such a tight cast who understood so much more. The audience also felt that way. I was approached personally and given positive feedback about how well the ensemble worked together. It was just great!

The students were uniformly interested in using Viewpoints again in further productions. Katrina claims she has already used Viewpoints in other directing projects, and Maclean has used them in work he has done with local high school theatre students. Alexander wants to use Viewpoints as a tool to create collaboration.

I think that if I was faced with a similar type of show, one with that much freedom of structure, I would certainly turn to Viewpoints in hopes of achieving the same 
level of unique collaboration that we did in this one. I've used Viewpoints on most of my work since. It's really helped me to manifest physically what I used to only capture mentally about my characters.

Conclusions. Marotta's use of Viewpoints in his production of Godspell allowed his cast to experience a profound and liberating method of performance. He explained some of the benefits of using Viewpoints:

Viewpoints created a context and vehicle to explore specific production goals. It built a useful common vocabulary for staging, evolving, and fixing our production, and made consistent movement and staging choices which fluidly fed into and off of musical numbers and dances. Viewpoints offered an opportunity to apply material, draw parallels, and directly connect and extend lessons from curriculum and classroom. Look, it's no secret that I had my reservations and doubts about the relevance and merit of the [Godspell] script and songs. This process helped me and the performers bring the show, the characters, and the songs alive in ways that made us all appreciate what the script can communicate to an audience. We went from not believing in the script to truly being excited about what we had to share with an audience. I strongly believe it was the effect of Viewpoints on the ensemble, and how closely our journey of exploring them paralleled the journey of the characters within the play.

This was supported by his student actors, who all felt that Viewpoints was well worth their time in the rehearsal process. Marotta may consider, however, taking more time to explain what each individual Viewpoint is, and how it works, so that they are clearer in his students' minds. Without a clear, cohesive explanation, these students may confuse Viewpoints with 
simple warm-up exercises, stretches, or games. It's important that his explanation helps the students link the process to the product. He may also wish to consider helping students like Katrina, who commented that for individual and couples work she would prefer other forms of connection, to understand that Viewpoints does not have to be used specifically by large groups. Viewpoints work can be effective in intimate or smaller-scale situations.

\section{Case Study: The Tempest}

My own experience with The Tempest at Utah Valley University during September and October of 2006 would precede and support what Marotta and Sanborn Jones found in their experiences with Viewpoints. I began each rehearsal with a series of Viewpoints exercises where students were allowed only to physically move around the stage, with no sound in the rehearsal space besides background music, which I provided. I introduced each Viewpoint to the cast separately, and then combined three or more until they could identify each of the nine Viewpoints and their relationship to each other. While the cast didn't know anything about Viewpoints and seemed initially hesitant to try it, I noticed that my students seemed to connect more powerfully with each other, with their text, and with their audience once we had moved through the series of exercises. Almost immediately these students began to show a freedom in performance that I had not seen before. They began to trust each other. More importantly, they began to open up to each other. Their performances took on an honesty and openness that was exciting to watch. Viewpoints took a group of inhibited young students and made them expressive, thoughtful, giving, and ultimately powerful in their performance.

Three of my student actors, whom I will call Brian, Todd, and Alan, were able to provide me some retrospective insight into their experience in rehearsal. None of them had any prior experience with Viewpoints, as it was a relatively new theory at the time and was not being 
taught in any of the UVU stage movement classes. The entire cast was introduced to Viewpoints together, which I found to be incredibly helpful in building ensemble.

This production of The Tempest was performed in a sort of puppetry reader's theatre. Silent actors, wearing masks, mimed the play from the stage while four "voice actors" read the lines aloud. Brian and Alan, both theatre majors from Provo, Utah, played two of the "voice" actors in the show. They were not actors on stage, but rather read all of the characters' lines just to the side of it. This required them to create individual voices for each of the eighteen characters in the play. Alan remembers relying specifically on tempo.

The exercise where the Voices read lines from Sylvia Plath's "Ariel” while the Movers improvised movements stands out to me. It was a great way to develop the relationships between Voices and Movers-especially in relation to tempo, duration, response, and repetition.

He also felt a physical connection to the "movers," the actors who physically enacted the play on stage, by using shape and gesture.

I think the voices were very sensitive to the shapes and movements the Movers came up with. We tried to respond to whatever they were giving us, and in turn, they were very good about incorporating whatever we came up with in terms of sound. This developed into a great relationship of Kinesthetic Response. We were always trying to vocalize the details of their movements, and they would physicalize the power of our words.

Brian also felt that Viewpoints helped him connect his words with the actors' movements.

Viewpoints helped provide a critical aspect of my performance in synchronizing 
Viewpoints: Liberatory Ensemble and Character

me with the action of the stage. I was on a lower plane than the performers and needed to connect with them in a way other than with my voice. Viewpoints provided another dimension, a separate playing field in which I maintained connection, engaged with the energy, and involved the actors with what I was doing below them.

Todd, a theatre major from Orem, Utah, who was a "mover," found that Viewpoints positively affected the ensemble of the show more effectively than him individually.

My personal Tempest character development probably wasn't affected as much as the sort of overall character of the cast. [Viewpoints] helped us to become "functional" as a single body. At times when a part of the body would consciously make a leading choice, the rest of the body members, now becoming more spatially aware of what our "cast body" limbs are doing, developed physiological reactions to the choice. At times it appeared magic.

These sentiments were echoed throughout the study, specifically by Andrew and Angela at BYU and Maclean, Alexander, and Katrina at SUU. It may be said that all three directors need to help students understand that Viewpoints can affect their individual work as much as their collective work. It is commendable that they are finding community and ensemble, but they should also be finding personal strengthening and creative expression.

Todd had initial difficulties with Viewpoints, because "it was new to me at the time and I had little practice letting go of fixed fears, emotions, and getting my critical mind to stop analyzing and start flowing in the actual moment. Sometimes it would just click, though." Later, however, Todd learned that kinesthetic response would occur when he learned to relinquish control and trust his fellow actors: 
I remember feeling the times where magic happened between the whole cast during Viewpoints and on stage. Unplanned spontaneous yet seemingly rehearsed expression would occur. They happened whenever "feeling" mind took over instead of critical mind.

Alan, who has since used Viewpoints in his student directing projects, felt that Viewpoints was essential in the building of "our very cohesive and collaborative ensemble" and “gave us the 'language' and shared experience of the development process from which we sculpted the final product." While Brian, who has since graduated and now works in the field of motivational training, claims that "there is a viable force given from Viewpoints exercises. This is a highly valuable tool for the actor to engage connection and correspondence with others working in the scene of a show."

I felt that, while I could have done a much better job introducing each individual to Viewpoints and could have helped my actors find a personal connection to their characters rather than just a communal connection to the play, I was ultimately successful in helping students understand the importance of interaction and physical conduct. The play was invited to perform in its entirety at the Kennedy Center American College Theatre Regional Festival in 2007, and I received the National Kennedy Center Distinguished Directing Award. But perhaps more importantly, these students had a liberatory experience that impacted how they created and understood the meaning of conduct, both on stage and off.

\section{Conclusion}

Since most college and university theatre professors are hired not only to teach, but also to produce theatre for the school, and their production (and the quality thereof) is often factored into their reappointment, tenure, and promotion, college directors must produce theatre pieces 
that are commercially viable and of strong artistic merit but that can also teach and train student actors to become professionals. The problem of how also to create fulfilling experiences for students is compounded by time, university expectations, and resources. Introducing Viewpoints into the college rehearsal is effective in the following ways:

1. Students who use Viewpoints in rehearsal find greater self-confidence, stronger sense of character, and a more cohesive experience with the cast. They experience a stronger "buy in" with the production because they feel like they are an intimate part of its creation.

2. Viewpoints proves to be a liberatory experience; several of the students in the examples studied mentioned that they felt physically and emotionally "free" to explore and create. The rehearsal hall became a Studio Classroom where students learned through doing; there were fewer lectures and more impulsive exploration. Students had a greater sense of their role in both the process and the production.

3. These rehearsal processes are liberatory because they emphasize respect for human nature, needs, and struggle. They are rooted in the process of creation; they do not focus only on the end result. Rehearsals with Viewpoints became more democratic and humanizing. This only happened, however, when directors fully explained the goals and processes of Viewpoints. When they did not, students felt confusion of purpose.

4. Viewpoints was remarkably effective in creating a stronger sense of group. Students mentioned that Viewpoints created a "community" of performers who used a "unified vocabulary." One student remarked that he felt the entire group began to function as a single body, united in purpose. Several of the students mentioned that audience 
feedback confirmed the unified community they had created on stage.

5. Viewpoints increases comprehension of the work and self-actualization of the actors by opening them up to the text physically; they were not just reading and discussing their material, they were moving, creating, and physically exploring it. In the meantime, some actors felt that they became increasingly confident in their abilities on stage, and many of them expressed a newfound confidence in their talent.

6. Directors found that Viewpoints was able to create a workable, creative dynamic in very short periods of time - in the case of Godspell, in less than a week. This effectiveness is invaluable to directors who have limited access to rehearsal time with student actors. They can also know that the work they are creating is thoughtful, instinctual, and creative, and that this will translate to the stage.

Anne Bogart's Viewpoints opens actors up to the idea that their voice is valid and resonant in the process of creating theatre. It encourages them to collaborate in an environment that has been, in times past, dictatorial or passive. It also helps actors to recognize meaning in everything they do on stage. They can identify their physical choices and assign them meaning, which can be used in the final product to help an audience understand the same meaning. Viewpoints encourages discipline, but it also encourages unbridled, liberatory creativity. Using creative play helps directors unlock ideas, suggestions, and impulses that actors may otherwise hide or withhold. These experiences give actors, and in particular student actors, the confidence they need to continue on a creative path. It also gives actors both a tangible way to find characters and a formative way to understand themselves, as echoed by Freire (2000): "to affirm that men and women are persons and as persons should be free, and yet to do nothing tangible to make this affirmation a reality, is a farce" (p. 50). 
Viewpoints: Liberatory Ensemble and Character

It is important, therefore, that directors create the correct environment for these exercises to happen. Directors who choose to use Viewpoints to turn the rehearsal hall into a studio classroom will find student actors who are more comfortable, more responsive, and more willing to account for their work and actively participate in the process of theatre. These students will have a liberatory experience, where they can collaborate, create, and express ideas, and where they come to understand who they are as individuals, what they can become as characters, and what they can do as a team. 
Viewpoints: Liberatory Ensemble and Character

\section{References}

Arnheim, R. (1997). Visual thinking. Los Angeles, CA: University of California Press.

Barry, A. (1997). Visual intelligence: Perception, image, and manipulation in visual communication. Albany, NY: State University of New York Press.

Blumer, H. (1986). Symbolic interactionism: Perspective and method. Berkeley, CA: University of California Press.

Bogart, A. (2001). A director prepares: Seven essays on art and theatre. London, United Kingdom: Routledge.

Bogart, A. (2007). And then, you act: Making art in an unpredictable world. London, United Kingdom: Routledge.

Bogart, A., \& Landau, T. (2005). The Viewpoints book. New York, NY: Theatre Communications Group.

Brook, P. (1996). The empty space: A book about the theatre: deadly, holy, rough, immediate. New York, NY: Touchstone.

Campbell, J. (2008). The hero with a thousand faces. Novato, CA: New World Library.

Denzin, N., \& Lincoln, Y. (2011). The SAGE handbook of qualitative research. Thousand Oaks, CA: Sage.

Freire, P. (2000). Pedagogy of the oppressed (30th Anniversary Ed.). New York, NY: Continuum.

Freire, P., \& Shore, I. (1986). A pedagogy for liberation: Dialogues on transforming education. New York, NY: Bergin \& Garvey.

Goffman, E. (1966). Behavior in public places: Notes on the social organization of gatherings. New York, NY: Simon \& Schuster. 
Viewpoints: Liberatory Ensemble and Character

Gordon, R. (2006). The purpose of playing: Modern acting theories in perspective. Ann Arbor, MI: University of Michigan Press.

Griffin, E. (2012). A first look at communication theory. New York, NY: McGraw-Hill.

Hetland, L., Winner, E., Veenema, S., \& Sheridan, K. (2007). Studio thinking: The real benefits of visual arts education. New York, NY: Teachers College Press.

Hewitt, J. P. (2000). Self and society: A symbolic interactionist social psychology. Boston, MA: Allyn and Bacon.

hooks, b. (1994). Teaching to transgress. New York, NY: Routledge.

Jaynes, J. (1990). The origin of consciousness in the breakdown of the bicameral mind. New York, NY: Houghton Mifflin.

Kingdon, T. (2004). Total directing: Integrating camera and performance in film and television. Los Angeles, CA: Silman-James Press.

Krasner, D. (2006). American drama 1945-2000: An introduction. Malden, MA: Blackwell.

Manis, J. G., \& Meltzer, B. N. (Eds.). (1967). Symbolic interactionism: A reader in social psychology. Boston, MA: Allyn and Bacon.

Mead, G. H. (1967). Mind, self, and society: From the standpoint of a social behaviorist. Chicago, IL: University of Chicago Press.

Millman, D. (1999). Body mind mastery: Creating success in sport and life. Novato, CA: New World Library.

Nachmanovitch, S. (1990). Free play: Improvisation in life and art. New York, NY: Putnam Penguin.

Rimer, J., \& Masekazu, Y. (1984) On the art of the no drama: The major treatises of Zeami. Princeton, NJ: Princeton University Press. 